\title{
Exploring patterns of multiple climates and their effects on safety performance at the department level
}

\author{
Anna Paolillo ${ }^{\mathrm{a}, *}$, Silvia A. Silva ${ }^{\mathrm{b}}$, Helena Carvalho ${ }^{\mathrm{c}}$, Margherita Pasini ${ }^{\mathrm{d}}$ \\ a Department of Management, Kingston Business School, Kingston University London, Kingston Hill, Kingston upon Thames KT2 7LB, United Kingdom \\ ${ }^{\mathrm{b}}$ Instituto Universitário de Lisboa (ISCTE-IUL), BRU-IUL, Portugal \\ ${ }^{\mathrm{C}}$ Instituto Universitário de Lisboa (ISCTE-IUL), CIES-IUL, Portugal \\ ${ }^{\mathrm{d}}$ Department of Philosophy, Education and Psychology, University of Verona, Italy
}

\section{A R T I C L E I N F O}

\section{Article history:}

Received 12 February 2019

Received in revised form 12 August 2019

Accepted 11 December 2019

Available online 3 January 2020

\section{Keywords:}

Safety

Diversity

Inclusion

Communication

Climate

\begin{abstract}
A B S T R A C T
Introduction: This paper represents a first attempt to fill a gap in research about different specific climates and safety outcomes, by empirically identifying patterns of climates and exploring the possible effect of different climates at the department level on some specific safety outcomes. The first objective was to explore how different specific climates (safety, communication, diversity and inclusion) can be associated to each other, considering the department level of analysis. The second objective was to examine the relationships between those patterns of climates with safety performance (compliance and participation behaviors). Method: A total of 429 blue-collar workers in 35 departments answered a questionnaire covering safety, diversity, inclusion, and communication climate measures. Cluster analysis was performed to identify clusters of departments with different climate patterns and their impact on safety compliance and safety participation behaviors. Subsequently, a hierarchical multiple linear regression was conducted at the individual-level to test the effect of climate patterns, by controlling for some sociodemographic variables. Results: Results showed the existence of four differentiated clusters of departments. Three of those clusters showed homogenous patterns (coherent association among perceptions of low, medium and high climates) and one heterogeneous (low and medium perceptions). The findings also revealed that the higher the climates perceptions, the higher the levels of safety participation and safety compliance, with safety participation being more affected than compliance. Conclusions: The present research showed the associated effects of some organizational climate factors, such as fair treatment, inclusion, safety and communication within the organization, which had not been previously studied in their combined relationships, on safety behaviors. Practical applications: Several other organizational climate factors, such as fair treatment, inclusiveness and communication, may play an important role in safety, showing the importance of broadening the focus on safety climate as one of the main predictors of safety behaviors. (c) 2019 National Safety Council and Elsevier Ltd. All rights reserved.
\end{abstract}

\section{Introduction}

Occupational injuries are multi-factorial occurrences within the working population that have a heavy impact on workers, companies, and society. Eurostat has published standardized statistics for fatal injuries across EU countries. There were 3,876 fatal injuries at work in the EU-28 during 2015, an increase of 102 deaths compared with the year before (EUROSTAT, 2018). Although much progress has been made as a result of improving preventive measures, fatality and injury rates may be described as unacceptably high (Konkolewsky, 2004). For that reason many studies in the past

\footnotetext{
* Corresponding author.

E-mail address: a.paolillo@kingston.ac.uk (A. Paolillo).
}

decade focused on the attempt to better understand which organizational factors have an impact on workplace safety.

Concerning the role of organizational factors, much of the research has focused on the construct of safety climate (e.g., Hofmann, Jacobs, \& Landy, 1995; Shannon, Mayr, \& Haines, 1997). Specifically, research has been supporting the important role of safety climate in understanding safety performance (e.g., Christian, Bradley, Wallace, \& Burke, 2009; Clarke, 2006; Hofmann, Burke, \& Zohar, 2017; Jiang, Lavaysse, \& Probst, 2019). Namely, safety climate has been linked to a number of different safety-related outcomes, showing its ability to predict important safety-related outcomes, such as perceived risk and injuries (e.g., Cooper \& Phillips, 2004; Hofmann \& Stetzer, 1996; Oliver, Cheyne, Tomas, \& Cox, 2002; Silva, Lima, \& Baptista, 2004). Relevant syntheses of studies concerning the effect of safety climates 
have been reported in reviews and meta-analyses (e.g. Beus, McCord, \& Zohar, 2016; Burke \& Signal, 2010; Casey, Griffin, Flatau Harrison, \& Neal, 2017; Christian et al., 2009; Clarke, 2006, 2010; Cornelissen, Van Hoof, \& De Jong, 2017; Glendon, 2008; Griffin \& Curcuruto, 2016; Guldenmund, 2000; Jiang et al., 2019; Nahrgang, Morgeson, \& Hofmann, 2011; Schonfeld \& Chang, 2017). Nevertheless, those meta-analytic studies and reviews reveal that many issues remain unexplored.

The first issue concerns the recent changes in the focus of climate research, as "researchers have switched their focus from global to facet-specific climates" (Kuenzi \& Schminke, 2009, p. 636). Specifically, facet-specific climates follow on from the idea that organizations can be viewed as having a number of climates pertaining to specific aspects, such as a climate for safety (Zohar, 2000), a climate for diversity (Mor Barak, Cherin, \& Berkman, 1998), a climate for communication (Smidts, Pruyn, \& Riel, 2001), and so forth. It follows that many of these facet-specific climates may simultaneously be present in a given work environment, as they refer to different aspects of the same organizational context (Kuenzi \& Schminke, 2009). Some authors have argued that it is meaningless to speak about organizational climate without attaching some type of specific referent (Schneider \& Reichers, 1983); for that reason, considerable research has explored the impact of facet-specific climates on parallel facet-specific outcomes (e.g. safety climate as a predictor of safety-related outcomes; Hofmann \& Stetzer, 1996; Oliver et al., 2002). As suggested by Kuenzi and Schminke (2009), this makes sense not only theoretically, but also statistically; indeed, "as Campbell (1990) notes, when the latent structure underlying both the predictor and outcome are similar, correlations between variables will be stronger" (p. 694). Furthermore, the authors suggested that many facetspecific climates have shown to influence some distinct outcomes as well (e.g., diversity climate was positively related to store unit sales performance; McKay, Avery, \& Morris, 2009); nevertheless the research in this area is still scarce, therefore inviting to explore those possibilities more in depth and not only focusing on the relationship between facet-specific climate and its directly related outcomes (e.g., safety climate as the leading predictor of safety behaviors and safety outcomes; Meliá, Mearns, Silva, \& Lima, 2008; Zohar \& Tenne-Gazit, 2008).

The focus on global climate versus facet-specific climate (Kuenzi \& Schminke, 2009), which the present study refers to, has to be distinguished from the measurement issue, reported in the literature, regarding generic versus industry-specific safety climate assessments. With reference to the latter, previous research (Huang et al., 2013; Zohar, 2010b) has suggested the need for measurement of industry-specific safety climates, depending on the different types of industries and on their context-dependent climate perceptions. The present paper does not focus on this measurement issue.

Additionally, the literature has started to consider the potential mutual influences of global and specific climates on each other but research in this area is only in its beginning, merely indicating the existence of multiple climates inside the same organization. Specifically, Wallace, Popp, and Mondore (2006) demonstrated that two foundational climates (management-employee relations and organizational support, as general foci climates) were related to safety climate, which, in its turn, was related to lower injury rates. It is therefore reasonable to examine what happens when different climates exist simultaneously (Kuenzi \& Schminke, 2009). More recently, Paolillo, Silva, and Pasini (2016), empirically tested the impact of psychological diversity climate and inclusion climate on safety behaviors in the manufacturing sector through the mediating role of safety motivation; the authors specifically found that the two climates have different and important impacts on safety. In particular, climate for inclusion showed to have a stronger rela- tionship with safety behaviors than diversity climate, probably due to its broader nature, related to support and quality of social exchange (both elements which safety performance is strictly dependent on; Wallace et al., 2006; Zohar \& Luria, 2005).

Recently, Törner, Pousette, Larsman, and Hemlin (2016) found that different specific organizational climates (safety, occupational health, innovativeness, and production effectiveness) were captured in a second-order climate of perceived organizational support (POS) and that this climate predicted team production effectiveness, team innovations, and employees' health and safety. More recently, Kim and Chung (2019) expanded the boundaries of research on organizational safety by demonstrating that a distal factor - namely perceived organizational justice, which is not directly related to safety performance - was associated with fewer traffic injuries.

Another issue concerns the importance of taking in to account the multilevel dimension of climate. Many scholars have emphasized that organizational processes take place simultaneously at various levels and that processes at different levels are linked in some way (e.g., Kozlowski \& Klein, 2000). Considering safety climate, for instance, at the organizational level, top managers elaborate policies and procedures; at a lower level (group-level), supervisors execute these policies and procedures, transforming them into practices. Assuming the capability of employees to distinguish between procedures defined by top management and the way supervisors execute them, it is possible to understand the important cross-level phenomenon of group level variation within a single organization-level climate (Zohar, 2010b). Zohar and Luria (2005) suggested that safety climate relates to socially constructed indications of desired behaviors, arising simultaneously from policy and procedural actions of top management and from practices of the supervisors. This implies that at least two climates must be considered: the one generated at the organizational level, concerning workers' perceptions of the top management's policies and procedures, and the one generated at the group level, that is workers' perceptions of how the supervisors transform those policies and procedures into daily practice. Considering the current state of art in the safety climate literature, as explained in the above paragraph, safety climate has been re-defined, in the last 15 years, as a multilevel construct (Glendon, 2008; Meliá et al., 2008; Zohar, 2000, 2008, 2010b, 2014; Zohar \& Luria, 2005). More recently, this multilevel perspective led to an increased awareness about the importance to consider safety climate not as individual perceptions, but as a group-level construct and therefore to be measured at the group-level; this, in turn, called for the need to perform cross-level statistical analyses in order to investigate how such processes happening at the group level can predict those ones happening at the individual level (e.g., personal resources and safety behaviors). Beus et al. (2016) stressed that "this would likewise bolster empirical findings because the independent variables would be assessed at the appropriate theoretical level of analysis" (p. 363).

It is worthwhile to note that the group-level climate is generated not only by supervisor's practices, but also by the group itself, given the influence of social norms on safety (e.g., Fugas, Meliá, \& Silva, 2011; Zohar \& Luria, 2005). Previous research has suggested the relevant role of the group processes and coworkers' support on safety (e.g., Hofmann \& Stetzer, 1996; Nahrgang, Morgeson, \& Hofmann, 2011). However, only some studies included co-wokers in the safety climate measures (e.g., Brondino, Silva, \& Pasini, 2012; Hahn \& Murphy, 2008; Meliá et al., 2008); the larger majority of the studies gave a higher emphasis to the leadership perspective, considering the supervisor as "enough" to represent the group climate (Brondino et al., 2012, p. 1848). Nevertheless, contributions from classic research and strong evidence from social and organizational psychology, highlighted the need to consider the 
influence of coworkers on group safety climate (e.g., Bandura, 1986; Fugas et al., 2011), as they: offer information, show behavioral support for desired practices while discouraging others, and might shape their peers' roles by offering lateral mentoring (e.g., Chiaburu \& Harrison, 2008). Since a large part of the research about safety climate has not systematically included coworkers, it is essential to study group safety climate by taking into account what a group values and by distinguishing between the role of the supervisor and that of coworkers (Brondino et al., 2012).

Therefore, this is the first study, at the best knowledge of the authors, which explores the combined effect of different climates on some specific safety outcomes at the department level. It aims to explore what specific climate patterns exist considering safety, communication, diversity and inclusion, at the department level of analysis and to examine how different department climate patterns may be associated with safety performance (compliance and participation behaviors). Specifically, while in some departments the patterns of climates may be very high, in others they may be very low, and in other departments there may be a combination of different levels of climate perceptions that will possibly have a different impact on safety outcomes.

The study of safety performance has a long and solid evolution with significant contributes to injuries prevention. In the earlier days the focus was on developing legislation and understanding the exposition to a large variety of risks and the consequent need to protect workers from those workplace risks. Those efforts were followed by research revealing that individual differences also predicted safety at work. More recently (in the latter years of the 20th century) there was a noteworthy increase of studies highlighting the management and organizational environmental factors in occupational illnesses and, in this context, the construct of safety climate become critically important (Hofmann et al., 2017; Zohar, Huang, Lee, \& Robertson, 2015). Considering this framework, it was decided to keep safety climate among the specific climates that can interact in explaining some safety outcomes. Then, and in order to create synergies with other theoretical perspectives, the issue of employees' perceptions about diversity, inclusion, and communication in the workplace was chosen for special attention, considering the Zwetsloot, van Scheppingen, Bos, Dijkman, and Starren (2013) findings. Specifically, the authors identified the core values supporting health, safety, and well-being at work; it appeared that interconnectedness (e.g., social support), participation (e.g., empowerment, social inclusion) and trust (respect) characterized the first values cluster of positive attitude toward people and their being (Zwetsloot et al., 2013). At the same time, justice (e.g., diversity, equity, fairness) and responsibility (e.g., transparency and openness in communication) made up the second values cluster of valuing people actions and their doing (Zwetsloot et al., 2013). Moreover, many studies have examined the nature of the effects of diversity on individual, team, and organizational level outcomes (including safety), but no research has considered the role of shared perceptions about diversity within organizations (which form a climate for diversity, Mor Barak et al., 1998) concerning its consequences on employees' work attitudes and performance related to safety.

The construct of inclusion climate (Shore et al., 2011), was also considered in the present study as being related to safety; specifically it is based on the employees' perceptions of being involved in decision making and information networks and being able to actively participate in social and informal organizational activities, regardless of the individual's belonging to a specific demographic group. This kind of social empowerment, which has been shown to influence other work outcomes (Glisson \& James, 2002; Nissly, Mor Barak, \& Levin, 2005), was considered in the present research to have the potential to influence some safety outcomes; specifi- cally it was hypothesized that it could influence the workers' involvement and commitment to safety and their safety performance. Finally, perceptions of a supportive, open and trustworthy organizational communication, together with an effective exchange of information, namely a positive communication climate (Smidts, Pruyn, \& Riel, 2001) appears to impact on safety climate and it helps to develop a participative organizational culture for safety (Cheyne, Cox, Oliver, \& Tomas, 1998). It is also a core element of the perception of inclusiveness and integration of all workers within their organizations; for that reason, communication climate was also included in this study.

In the following section, each of the theoretical constructs mentioned above and the theoretical framework underlying this study is described.

\subsection{Safety climate}

Since the 1980s, research on safety at work has often focused on safety climate as an antecedent of safety performance, defining safety climate as the shared perceptions of policies, procedures, and practices relating to safety, which affect well-being at work (e.g. Griffin \& Neal, 2000; Zohar, 1980, 2003, 2010b). At the group level and basing on previous research, safety climate could refer to either supervisor's (e.g. Meliá \& Sesé, 2007; Zohar, 2000; Zohar \& Luria, 2005) or coworkers' practices (e.g. Brondino et al., 2012; Brondino, Pasini, \& Silva, 2013; DeJoy, Schaffer, Wilson, Vandenberg, \& Butts, 2004; Hahn \& Murphy, 2008; Jiang, Yu, Li, \& Li, 2010; Meliá et al., 2008; Nahrgang et al., 2011; Singer, Meterko, \& L, Baker L., Gaba, D., Falwell, A., \& Rosen, A. , 2007). It should also be emphasized that the relevance of coworkers on workers' health has been recognized since the early studies on stress and health behaviors at work (e.g., House, 1981; Johnson, 1988; Karasek \& Theorell, 1990; Silva \& Fugas, 2015; Viswesvaran, Sanchez, \& Fisher, 1999). Nevertheless, it is possible to recognize how until recently the influence of peers had received less systematic attention than the supervisor, and its impact on employees' safety behavior has been less covered in the safety climate measures (Fugas, Silva, \& Meliá, 2012).

Few studies in literature considered coworkers as a safety agent distinct from supervisor (e.g., Brondino et al., 2012, Bronkhorst, 2015; Meliá et al., 2008; Silva, Araújo, Costa, \& Meliá, 2013; Zhang, Pirzadeh, Lingard, \& Nevin, 2018). In line with the above mentioned studies, Chiaburu and Harrison (2008) showed that coworkers' support and antagonism have a clear effect on employees' outcomes outside of the one given by leaders, with coworkers' support having a strong positive relationship with task performance. Other studies focused on the role of the work-unit in improving safety: for example, shared mental models can affect group capacity to achieve safety outcomes (Marks, Mathieu, \& Zaccaro, 2001; Smith-Jentsch, Mathieu, \& Kraiger, 2005). Additionally, Meliá and colleagues (2008) showed that organizational safety climate and supervisor's safety climate positively and significantly predicted coworkers' safety climate, whereas Brondino et al. (2012) found that coworkers' safety climate had a stronger influence on safety-related behaviors than supervisors' safety climate. Additional studies showed the influence of peers on safety behaviors (e.g., Andriessen, 1978; Cree \& Kelloway, 1997; Tucker, Chmiel, Turner, Hershcovis, \& Stride, 2008; Westaby \& Lowe, 2005); for example, coworkers' safety support demonstrated to directly predict safety behaviors, in particular safety compliance and the use of personal protective equipment (Liu et al., 2015). Other research found that coworkers' safety practices were associated with injury outcomes, whereas safety practices related to contractors and union stewards were not (Kim, Dutra, \& Okechukwu, 2014). More recently, Andersen, Nørdam, Joensson, Kines, and Nielsen (2018) found that the indi- 
vidual perceptions of work group safety norms represent a stronger antecedent of workers' safety behavior, compared to perceptions of managements' safety norms.

Those studies are consistent with the theoretical arguments that coworkers are an important source of commitment (Reichers, 1985) and they stress, as suggested by Chiaburu and Harrison (2008), the importance for future research to simultaneously examining influences from different social agents (coworkers, supervisors, organization) and to understand if their influences are additive, interactive or compensatory. Specifically, the various configurations obtained by crossing positive and negative perceptions originating from one's organization, supervisor, and coworkers lead to different effects, which can be additive, synergistic or neutralizing (Chiaburu \& Harrison, 2008). For example, a high supervisor's commitment to safety may compensate the negative effect of a low organizational safety climate. Those simultaneous effects have been scarcely investigated and call for the need to use an integrated framework (which takes into consideration both vertical and lateral exchanges) in order to direct the focus of interventions. Therefore, the aim of the present study is to address those issues, by considering safety climate at the organizational, supervisor, and coworkers' levels.

\subsection{Communication climate}

Research into major organizational injuries in various sectors has highlighted the failure of communication processes both within and between organizations (Turner, 1978) as recurrent features contributing to such events. On the contrary, if employees perceive that there is open communication in the organization, then they may also perceive that communication about safety is valued in the organization (Neal, Griffin, \& Hart, 2000). Specifically for such perceptions, communication climate can be defined as a facet-specific climate that includes only communicative elements of a work environment. This encompasses perceptions about the receptivity of management to employee communication or the trustworthiness of the information being disseminated in the organization (Guzley, 1992). Several studies have shown the link between communication and safety (DeJoy et al., 2004; Hofmann \& Morgeson, 1999) and they concluded that communication was an important factor contributing to safety climate; specifically, DeJoy et al. (2004) found that communication and organizational support were the strongest contributors (after safety policies and programs) to employees perceptions of safety. A possible explanation for those results could rely on the fact that "a positive safety climate is more likely to exist in an environment that generally supports and values its employees and where there is open and effective exchange of information" (DeJoy et al., 2004, p. 88). The above-mentioned findings suggest that an open and effective communication is a key feature of a positive safety climate and indicative of a supportive work climate; therefore and interestingly, (as underlined by the authors), communication and organizational support are strictly related to safety but they are not specific to safety per se (as they are dimensions of general organizational climate; DeJoy et al., 2004). In social exchange terms (Blau, 1964; Eisenberger, Fasolo, \& DavisLaMastro, 1990), when employees perceive that their employer values and supports them, this engenders an implied obligation, on the part of employees, for future reciprocity that will benefit the organization in some way.

Therefore, it is reasonable to ask what kind of relationship communication climate could have with safety behaviors when combined with different patterns of low/high perceived organizational safety priorities.

\subsection{Diversity climate}

Recent studies have suggested that considering how workers perceive diversity management within their work organization as the workforce becomes more diverse (McKay et al., 2008, 2009), is an important aspect for improving organizational performance and promoting greater inclusion of employees from various backgrounds. Specifically, Mor Barak et al. (1998) have proposed that employees develop perceptions about the organizations' stance regarding diversity, as well as developing their own personal opinions about the value of diversity in a company, which have implications for organizational effectiveness, work attitudes and performance. Diversity climate is defined as "employee behaviors and attitudes that are grounded in perceptions of the organizational context related to women and minorities" (Mor Barak et al., 1998, p. 83). These perceptions can manifest themselves at an individual level, or at a social unit level (Stegmann, 2011). Specifically for safety performance, there is a number of research focusing on the impact of specific and objective kinds of diversity on occupational injuries and illnesses, such as gender (Bauerle, Mcgonagle, \& Magley, 2016; Karttunen \& Rautiainen, 2016; Smith \& Anderson, 2017; Tucker, Diekrager, Turner, \& Kelloway, 2014), ethnicity (Seabury, Terp, \& Boden, 2017; Tak, Alterman, Baron, \& Calvert, 2010) and age (Breslin \& Smith, 2005; Kachan et al., 2012; Smith \& Berecki-Gisolf, 2014). With regards to subjective perceptions about how diversity is valued, integrated and supported within the organization (namely a diversity climate; Kaplan, Wiley, \& Maertz, 2011) there are some previous studies showing that a climate for diversity can have implications for employees' wellbeing (Schonfeld \& Chang, 2017). Specifically, a high diversity climate can contribute to higher employee job satisfaction (e.g., Brimhall, Lizano, \& Mor Barak, 2014) and organizational attachment (Kaplan et al., 2011); at the same time, other organizational climates related to the fair treatment of employees (e.g., justice climate, Whitman, Caleo, Carpenter, Horner, \& Bernerth, 2012) have shown to be related to safety performance (Gatien, 2010) and safety injuries reporting (Beyea, 2004; Weiner, Hobgood, \& Lewis, 2008). However, as previously discussed, there is only one study about the relationship between diversity climate (of which the perception of fair treatment is only one component) and safety behaviors and it was specifically focused on psychological diversity climate and safety participation behaviors (Paolillo, Pasini, Silva, \& Magnano, 2016); the results showed that such climate perceptions led to an environment where people's well-being and safety were important, thereby motivating employees to voluntarily participate in safety enhancing behaviors. We therefore decided to expand the existing findings by focusing on diversity climate at the department level (rather than on objective categories of diversity) as linked to safety behaviors, because the shared perceptions of company's efforts towards diverse employees can be considered as an indicator of how much the company cares for its employees' wellbeing (Paolillo et al., 2016).

As for communication climate, Blau (1964) social exchange theory was applied in this context to theoretically sustain it. It is considered that, if group members perceive they are treated in a certain way, they should then similarly assign meaning to that treatment as representative of a social exchange relationship. Therefore, in the light of a positive treatment received from others, a reciprocal relationship is formed such that employees feel concern for one another and may be motivated to engage in safe behaviors, because they feel the company has their best interests at heart and they will feel the need to reciprocate by improving their attitudes toward safety. Considering the results of previous research, it makes sense to question what kind of contribution diversity climate can give to safety behaviors when combined with 
different patterns of low/medium/high safety climates and other "relational" climates (such as inclusion and communication climates).

\subsection{Inclusion climate}

There is a strong and consistent relationship between diversity and inclusion (Ibarra, 1993); research indicates that employees can feel excluded from networks of information and opportunity (O'Leary \& Ickovics, 1992) because of their actual or perceived membership in a minority or disfavored identity group (Milliken \& Martins, 1996). As suggested by Shore et al. (2011), shared perceptions of inclusion can build a climate for inclusion, which achieves the interpersonal integration and involvement in decision making of all social groups.

Recent literature considers climate for inclusion as broader in scope than diversity climate, because it requires more than increasing diverse representation and implementing fair human resource practices (as diversity climate does). It also "requires a change in interaction patterns" (Nishii, 2013, p. 1756) in terms of the workers' participation in the organizational structures and processes (formal and informal ones). Therefore, a climate for inclusion is more related to the process of empowerment and involvement of workers in decision making processes, information networks, and social and informal activities and not only to the specific issue of how to deal with organizational demography.

An employee's perception of inclusion has been found to influence work quality (Glisson \& James, 2002), workers' health and social functioning (McNeely, 1992) and well-being (Mor Barak \& Levin, 2002). Thus, employees may reciprocate a felt sense of inclusion by broadening their role definitions to include safety-related behaviors (Hofmann, Morgeson, \& Gerras, 2003); this kind of result can be particularly enhanced when a high sense of inclusion is combined with a high safety climate. Nevertheless, it might also be interesting to explore possible associations (if any) of climate for inclusion to the other distinct but related climates (climate for diversity and communication); specifically, the link between communication climate and diversity and inclusion climates is evident, since providing each employee with appropriate information and the opportunities to speak out, get involved in, be listened to, and actively participate in, may lead the employee to categorize him/herself more easily as a significant member of an in-group (a greater sense of being treated fairly and being involved in some critical organizational processes). Moreover, experiencing openness in communication with supervisors and colleagues may increase the employee's feelings of self-worth, because under such conditions she or he will experience being taken seriously (Smidts et al., 2001), thus enhancing the sense of inclusion and empowerment. It is also important to understand what kind of contribution those patterns of climates could have on safety compliance and participation when combined with the positive and negative influences originating from safety climates.

\subsection{Safety behaviors}

The most common indicators used to describe the level of workplace safety are safety behaviors. The role of employees' safety behaviors in determining a safe versus unsafe work environment is well recognized in the safety literature, and the predicting link between safety behaviors and workplace injuries has been demonstrated by various empirical studies, as highlighted by many metaanalytic works and reviews in this field (Beus, Dhanani, \& McCord, 2015; Beus et al., 2016; Christian et al., 2009; Clarke, 2006, 2010, 2012; Griffin \& Curcuruto, 2016; Nahrgang et al., 2011).

Safety performance can be considered as a part of work performance specifically related to safety. With reference to this, Neal and colleagues (e.g., Neal \& Griffin, 1997; Griffin \& Neal, 2000; Neal et al., 2000), talking about safety behaviors in the workplace, distinguished between safety compliance and safety participation; the first one referred to activities regarding adhesion and respect for correct and safe procedures and taking precautions against risks (such as using the proper protective equipment). The latter corresponded to behaviors that do not directly increase workplace safety, but that help to create an environment supportive of safety (such as helping coworkers and promoting voluntary safetyprograms). Although safety compliance involves engaging in behaviors that are recognized as part of an employee's job, safety participation involves a greater voluntary element, including behaviors beyond the employee's work role, that is, extra-role or organizational citizenship behavior - OCB (Clarke, 2006).

There is no research focused on the relationships between associations of facet-climates (i.e. climate patterns) and safety performance; therefore, the current study attempt to fill this gap.

Considering all these issues, the aims of the present study was to answer the research the following questions:

1. Which kind of specific climate patterns exist considering safety, communication, diversity and inclusion, at the department level of analysis?

2. How different department climate patterns may be associated with safety performance (compliance and participation behaviors)?

\section{Method}

Data were collected as part of a larger research project ("Safety Climate analysis in metal and mechanical sector: elaboration of better practices"), with two data collection periods.

\subsection{Participants}

Participants were 429 blue-collar workers of four small (from 0 to 50 employees), medium (from 50 to 200) and large (200 and beyond) Italian organizations, belonging to the metal-mechanical sector and working in different departments. From a geographical point of view, attention was focused on a specific zone, the region of Veneto in the North-East of Italy, an area among the highest for injuries rates at the workplace $25.1 \%$ of the total fatal injuries in Italy; National Institute for Insurance against Workplace Accidents and Occupational Disease, 2018) and a high level of industrial production, particularly in the manufacturing sector, which is one of the most important industrial sectors of this region (European Commission, 2018). Table 1 shows the characteristics of the four companies, whereas a complete list of each company's departments with number of workers per department is provided in the Appendix 1.

Of the employees, 406 (94.6\%), which belonged to 35 work departments, returned completed questionnaires. Each department was composed of individuals belonging to a specific division of the organization and dealing with defined tasks and sub-tasks pertaining a clear area of activity, and the number of workers per department ranged between 3 to 37 (mean department size $=11.6$, $\mathrm{SD}=8.8$ ).

All data were collected at an individual level. Considering the whole sample, $88.2 \%$ of the participants were male and $93.6 \%$ were Italian workers. For the other social and demographic characteristics of the sample: age $(19-25=7.4 \%, 26-35=23.4 \%, 36-$ $45=32.8 \%, \quad 46-55=29.3 \%$, over $55=7.1 \%$ ); religion (Catholic $=84.3 \%, \quad$ Atheist $=5.7 \%, \quad$ Orthodox $=3 \%, \quad$ Muslim $=2.3 \%$, Others $=4.7 \%$ ); educational level (number of school years: less than $5=1.5 \%, 5-8=24.4 \%, 9-13=62.1 \%$, more than $13=11.8 \%$ ). Further, $27.3 \%$ of respondents had worked for that company for 
Table 1

Characteristics of the companies.

\begin{tabular}{|c|c|c|c|c|}
\hline Company & Products & Company Size & Departments & Participants \\
\hline 1 & Generators and electric motors & Large & 17 & 244 \\
\hline 2 & Steam turbines & Large & 8 & 93 \\
\hline 3 & Shop equipments (shelving and check-out counters) & Medium & 6 & 58 \\
\hline 4 & Boilers & Small & 4 & 34 \\
\hline Tot & & & 35 & 429 \\
\hline
\end{tabular}

less than 5 years and $82.2 \%$ of the participants had a permanent contract.

\subsection{Procedure}

Participants answered the questionnaire during working hours, at the end or at the beginning of their work shift, and were asked to answer as sincerely as possible. They were ensured that all data were collected and conserved by the research group. They were also ensured that only aggregate results would be given to the management of the company. Along with the Italian questionnaire, English and French translations were also provided for foreign workers. Researchers were available to help participants, if necessary.

\subsection{Measures}

Safety climate. The Integrated Organizational Safety Climate Questionnaire (Brondino et al., 2013) that assesses, respectively: organizational safety climate (defined as shared perceptions about the real importance given to safety by the top management); supervisor's safety climate (defined as shared perceptions about the real importance given to safety by the employees' direct supervisor); and coworkers' safety climate (defined as shared perceptions about the real priority given to safety by an employee's colleagues), was used. The complete version of the Organizational Safety Climate scale (OSC) was used and it included 12 items with four factors: values ( $\alpha=0.84)$, safety systems ( $\alpha=0.84$ ), communication ( $\alpha=0.75$ ), and training ( $\alpha=0.83$ ). The complete version of the Supervisor's Safety Climate scale (SSC) was used and it included 10 items with two factors: values-safety systems $(\alpha=0.94)$ and coaching-communication $(\alpha=0.91)$. Also the complete version of the Coworkers' Safety Climate scale (CSC) was used and it included 12 items with four factors: Values ( $\alpha=0.87$ ), Safety Systems $(\alpha=0.91)$, Communication $(\alpha=0.86)$, and Mentoring $(\alpha=0.86)$. For each scale, the sub-scale "Values" consisted of items related to the real importance given to safety by top management/ supervisor/coworkers (e.g., "Top management considers a person's safety behavior when moving/promoting people"); the sub-scale "Safety Systems" consisted of items related to the importance that top management/supervisor/coworkers assign to the safety procedures, practices, and equipment connected to safety at work (e.g., "My direct supervisor makes sure we receive all the personal protective equipment needed to do the job safely"); Communication, consisted of items related to the quality of top management/super visor/coworkers' communication processes concerning safety issues (e.g., "My team members talk about safety issues throughout the work week"); then, the sub-scale "Training" was specific for the OSC as it considered the importance that top management places on safety training (e.g., "Employees receive comprehensive training in workplace health and safety issues"), whereas the "Coaching" and "Mentoring" subscales (respectively for SSC and CSC) considered the supervisor/coworkers activities aimed at helping their colleagues behave more safely (e.g., "If it is necessary, my team members use explanations to get other team members to act safely"). Each item was answered on a 7-point Likert scale (from 1="never" to 7="always"). Alpha reliability of each scale was, respectively, 0.94 for OSC, 0.96 for SSC and 0.95 for CSC.

Communication Climate. This was assessed using Smidts and colleagues' (2001) Communication Climate scale, comprising 15 items answered on a 5-point Likert scale (from 1="strongly disagree" to $5=$ "strongly agree"). The items represent three dimensions: trust and openness in communication (upward, downward, and horizontal, e.g., "When my colleagues tell me something, I trust them to tell me the truth"; $\alpha=0.77$ ); participation in decision making (having a say in the organization, e.g., "In this organization, I have ample opportunity to have my say"; $\alpha=0.51$ and mean inter-item correlation $=0.24$, within the recommended range $0.15-0.50$, Clark \& Watson, 1995); and supportiveness (the feeling of being taken seriously by other members of the organization, e.g., "If you say something here, you are taken seriously;" $\alpha=0.68$ and mean inter-item correlation $=0.19$ ). Alpha reliability of the scale was 0.80 .

Diversity Climate. The Italian version of the Diversity Climate Scale (Mor Barak et al., 1998; Italian adaptation by Paolillo et al., 2016) was used to measure diversity climate. Six items were used, in order to measure the organizational dimension of Diversity Climate, comprising two factors: fairness (e.g., "Managers here give feedback and evaluate employees fairly, regardless of the employees' race, gender, sexual orientation, religion, age, or social background"; $\alpha=0.82$ ). and inclusion (e.g., "The company spends enough money and time on diversity awareness and related training"; $\alpha=0.67$ and mean inter-item correlation $=0.40$ ). Each item was answered on a 6-point Likert scale (from 1="strongly disagree" to $6=$ "strongly agree"). Alpha reliability of the scale was 0.74 .

Inclusion Climate. Climate for Inclusion was assessed using the Mor Barak Inclusion-Exclusion scale (MBIE) (Mor Barak \& Cherin, 1998), made of 15 items answered on a 6-point Likert scale (from $1=$ "strongly disagree" to $6=$ "strongly agree"). It uses a matrix system of five work-organization system levels (work group, organization, supervisor, higher management, and social/informal). For each of these levels the respondent is asked to assess his or her perception of inclusion across the following three dimensions: the decision-making process (e.g., "I have influence in decisions taken by my work group regarding our tasks"; $\alpha=0.73$ ); the information networks (e.g., "I am always informed about informal social activities and company social events"; $\alpha=0.60$ and mean interitem correlation $=0.19$ ) . and the level of participation/involvement (e.g., "I am typically involved and invited to actively participate in work-related activities of my work group"; $\alpha=0.70$ ). Alpha reliability of the scale was 0.83 .

Safety compliance. This was measured with a 4-item scale, ranged on a 7-point Likert scale (from 1="not at all" to 7="very much"). It is an Italian version (Brondino, 2011) of Griffin and Neal (2000, personal communication) scale about safety behavior. It assesses individual compliance to safety procedures (e.g. "I use all the necessary safety equipment to do my job"). Alpha reliability of the scale was 0.85 .

Safety participation. This was measured with an adjusted version of Griffin and Neal (2000, personal communication) scale about safety behavior (Brondino et al., 2012). It is comprised by four items, answered on a 7-point Likert scale (from 1="not at all" to $7=$ "very much"), which assessed the employee's participation in 
activities which help to develop an environment that supports safety but does not directly contribute to safety performance (e. g, "I voluntarily carry out tasks or activities that help to improve workplace safety”. Cronbach's Alpha was 0.72 .

All the Alpha reliabilities are calculated on the individual scores across the entire sample.

\subsection{Data analysis}

First, the composition of the departments was analyzed. As we stated before, each department was composed of blue-collars dealing with defined tasks and sub-tasks pertaining a specific area of activity. This means that each department can be considered as a work-unit from a practical point of view. From a statistical point of view, some preliminary analyses were performed to verify whether the department members showed enough withindepartment homogeneity and between-department variance to justify the use of a department-level analysis.

Homogeneity of climate perceptions was assessed with $r_{w g}$ (James, Demaree, \& Wolf, 1993), intraclass correlation (ICC[1]), and reliability of the mean (ICC[2]; James, 1982; Shrout \& Fleiss, 1979). Methodological implications of homogeneity statistics are debatable. Lindell and Brandt (2000) have suggested that homogeneity statistics merely reflect the extent of consensus (e.g., climate strength) and should not be considered as an aggregation criterion. $\mathbf{R}_{w g}$ interpretation was made according to Dunlap, Burke, and Smith-Crowe (2003) critical values of the $r_{w g}$ statistic, considering the department size and the number of categories; results in our sample suggest acceptable homogeneity, i.e.: median $r_{w g}=0.71$ for OSC, 0.51 for SSC, 0.63 for CSC, 0.68 for diversity climate, 0.85 for inclusion climate and 0.55 for communication climate. Moreover, $\operatorname{ICC}(1)=0.08$, and $\operatorname{ICC}(2)=0.63$ for OSC, $\operatorname{ICC}(1)$ $=0.10$, and $\operatorname{ICC}(2)=0.69$ for $\operatorname{SSC}, \operatorname{ICC}(1)=0.05$, and $\operatorname{ICC}(2)=0.54$ for CSC, ICC $(1)=0.05$, and $\operatorname{ICC}(2)=0.50$ for diversity climate, ICC $(1)=0.11$, and $\operatorname{ICC}(2)=0.73$ for inclusion climate, $\operatorname{ICC}(1)=0.06$, and $\operatorname{ICC}(2)=0.55$ for communication climate. Together, the results indicate that there was a sufficiently high within-department homogeneity and between-department variance to warrant department-level analysis.

To identify types of departments with different climate patterns, a cluster analysis was performed, by using the six original answering scales - organizational, supervisor's and coworkers' safety climates, as well as diversity, inclusion and communication climates - as input variables. Since those scales had different ranges, firstly they were standardized with a normalization method, because they presented a normal distribution. Then, a hierarchical cluster analysis was conducted and two different agglomerative methods were used to find a more accurate solution, specifically the Ward's method and the between-groups linkage method (Hair, Anderson, Tatham, \& Black, 2010). After obtaining a convergent solution, an optimization algorithm (k-means) was used to cluster the departments; this method defines the final partitioning of the departments and allows each cluster (type) to be associated with a different climate pattern. Then, a parametric analysis of variance (ANOVA) was used to contrast the different patterns of climates according to safety performance (compliance and participation) at the individual-department level. A hierarchical multiple regression was also conducted at the individual-level to test the climate patterns effect on safety performance, controlling the effect of the sociodemographic variables. A categorical regression (CATREG) was used because it was necessary to accommodate nominal and ordinal independent variables (Gifi, 1990; Van Der Kooij, Meulman, \& Heiser, 2006).

Other well-known analytical tools, such as descriptive statistics, correlations and confirmatory factorial analysis (with maximum likelihood extraction method) were also used.
Data analysis was conducted by IBM-SPSS Statistics (version 24) and AMOS (version 24, Arbuckle, 2016).

\section{Results}

Descriptive statistics and correlations between variables are presented in Table 2. Given the high correlations (above 0.70 ) between the organizational safety climate scale and the coworkers' safety climate scale, a confirmatory factorial analysis (CFA) with maximum likelihood extraction method was conducted on the two scales and it confirmed that they were different constructs $\left(\chi^{2}(235)=883.19, \quad p<.001 \quad\right.$ and $\quad \chi^{2} / d f=3.758 ; \quad$ CFI $=0.93$; $\mathrm{TLI}=0.91$; SRMR $=0.05$; RMSEA $=0.08$ ). For the same reason, a CFA was applied on the diversity, inclusion and communication climates scales, and it confirmed that they were three different constructs $\left(\chi^{2}(657)=1696.44, p<.001\right.$ and $\chi^{2} / d f=2.582 ;$ CFI $=0.83$; $\mathrm{TLI}=0.81 ;$ SRMR $=0.08$; RMSEA $=0.06$ ).

Cluster analysis grouped the 35 departments into four types (clusters) according to their climate pattern (Fig. 1). Type 1 (four departments, $11.4 \%$ of the whole sample) shows a pattern that associates homogeneous low levels of climate perceptions (for instance, low perceptions of inclusion, communication, diversity, organizational, coworkers and supervisors' safety climates). Type 2 (ten departments, $28.6 \%$ of the whole sample) is characterized by a heterogeneous pattern, as it includes low perceptions of communication climate and organizational and supervisor's safety climates, together with medium perceptions of inclusion, diversity and coworker's safety climates. Type 3 (fifteen departments, $42.9 \%$ of the whole sample) shows again a homogeneous pattern which associates medium levels of perceptions for all climates (safety, diversity, inclusion, and communication). Finally, type 4 (six departments, $17.1 \%$ of the whole sample) reinforces another homogeneous pattern but with high levels of climate perceptions for diversity, inclusion, communication and safety climates.

Additionally, cluster analysis revealed that multiple climate patterns exist in the same company, with small and medium companies showing the co-existence of two types of climate patterns, whereas big companies having three to four different types of patterns existing simultaneously (within each company and across multiple departments). For more detailed information about the specific companies and departments distribution per climate pattern, please see Appendix 2.

A second step was to analyze the impact of those different climate patterns on safety outcomes. Fig. 2 shows the mean values of safety compliance and safety participation for the four different groups of climate pattern; the figure shows that safety compliance behavior had higher mean values than safety participation behavior for all the four types (clusters) of departments.

After, two one-way ANOVAs were conducted at the individuallevel, with the two safety behaviors (compliance and participation) as dependent variables, and the cluster as between-subject factor, with four level. The results showed that the pattern of climates had a significant effect on both safety compliance and on safety participation behaviors $\left(\mathrm{F}(3,402)=7.398, p<0.001, \eta^{2}=0.052\right.$ and $\mathrm{F}(3$, $402)=18.060, p<0.001, \eta^{2}=0.119$, respectively).

Post hoc comparisons (Scheffe's test) were performed, and several significant contrasts were found:

- Safety compliance behavior was significantly higher in type 1 in contrast with types 2 and 3 (Mean dif. type 1 vs type $2=0.34$, $p=0.002$; Mean dif. type $1 v$ s type $3=0.46, p=0.033$ ), and also in type 4 in contrast with type 2 and 3 (Mean dif. type $4 \mathrm{vs}$ type $2=0.47, p=0.005$; Mean dif. type 4 ss type $3=0.59$, $p=0.016)$; 
Table 2

Descriptive and correlations between the variables.

\begin{tabular}{|c|c|c|c|c|c|c|c|c|c|c|}
\hline Variables & M & SD & 1 & 2 & 3 & 4 & 5 & 6 & 7 & 8 \\
\hline 1. Organizational safety climate & 4.70 & 1.38 & $(0.94)$ & $0.69^{* *}$ & $0.52^{* *}$ & $0.43^{* *}$ & $0.46^{* *}$ & $0.53^{* *}$ & $0.57^{* *}$ & $0.74^{* * * *}$ \\
\hline 2. Supervisor's safety climate & 4.58 & 1.13 & $0.77^{* * *}$ & $(0.96)$ & $0.55^{* *}$ & $0.40^{* *}$ & $0.44^{* *}$ & $0.50^{* *}$ & $0.46^{* *}$ & $0.54^{* *}$ \\
\hline 3. Coworkers' safety climate & 4.37 & 1.23 & $0.48^{* *}$ & $0.39^{*}$ & $(0.95)$ & $0.42^{* *}$ & $0.44^{* *}$ & $0.41^{* *}$ & $0.41^{* *}$ & $0.71^{* * *}$ \\
\hline 4. Diversity climate & 3.96 & 3.26 & $0.52^{* *}$ & $0.46^{* *}$ & $0.59^{* * * *}$ & $(0.74)$ & $0.56^{* *}$ & $0.52^{* *}$ & $0.42^{* *}$ & $0.55^{* *}$ \\
\hline 5. Inclusion climate & 2.94 & 3.24 & $0.66^{* * *}$ & $0.55^{* *}$ & $0.61^{* * *}$ & $0.75^{* * *}$ & $(0.83)$ & $0.64^{* *}$ & $0.55^{* *}$ & $0.72^{* * *}$ \\
\hline 6. Communication climate & 2.98 & 2.95 & $0.55^{* *}$ & $0.57^{* * *}$ & $0.48^{* *}$ & $0.62^{* * *}$ & $0.76^{* *}$ & $(0.80)$ & $0.44^{* *}$ & $0.56^{* *}$ \\
\hline 7. Safety compliance & 5.76 & 0.87 & $0.46^{* *}$ & $0.41^{* *}$ & $0.36^{* *}$ & $0.19^{* *}$ & $0.21^{* *}$ & $0.23^{* *}$ & $(0.85)$ & $0.74^{* * *}$ \\
\hline 8. Safety participation & 5.01 & 1.08 & $0.55^{* *}$ & $0.50^{* *}$ & $0.60^{* * * *}$ & $0.35^{* *}$ & $0.44^{* *}$ & $0.35^{* *}$ & $0.61^{* * *}$ & $(0.72)$ \\
\hline
\end{tabular}

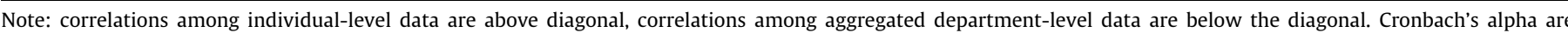
reported in diagonal in brackets.

$p<0.05^{* *} p<0.01{ }^{* * *} p<0.001$.

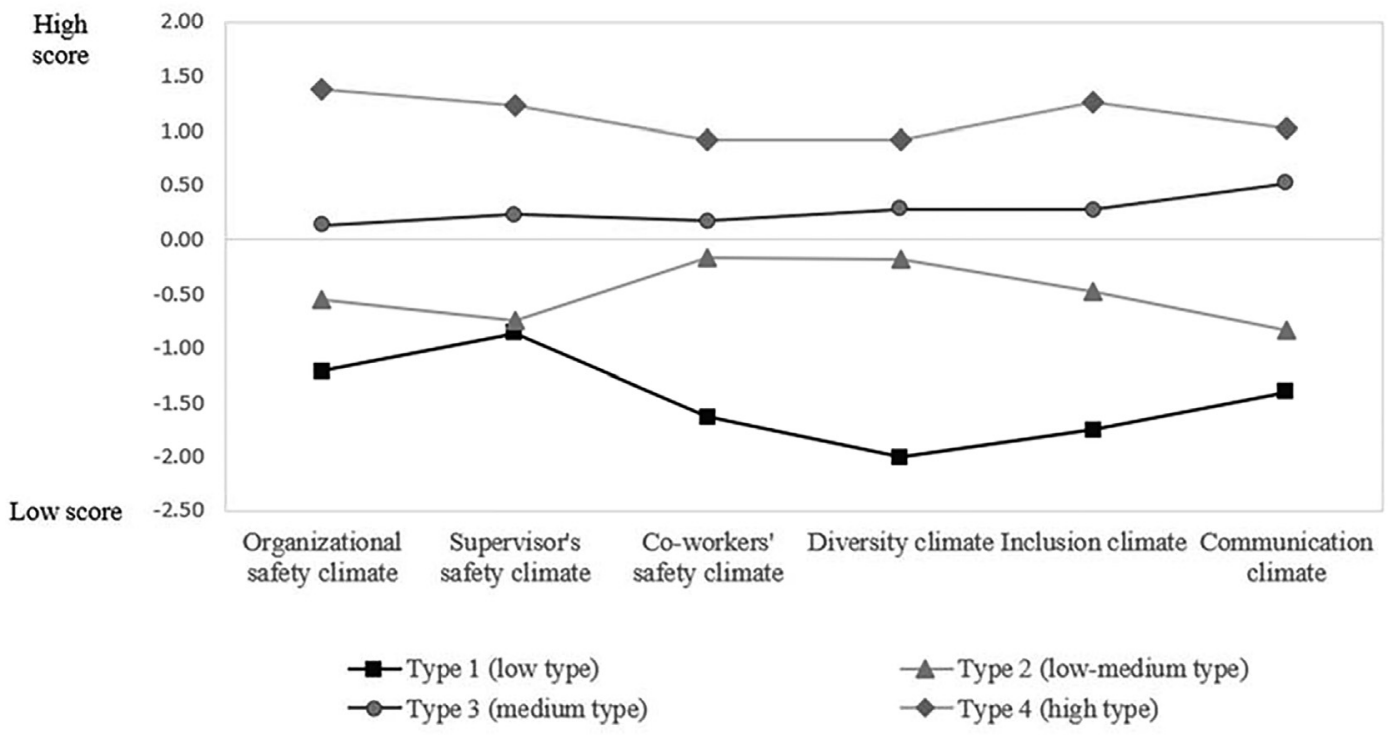

Fig. 1. Climate patterns by types (clusters) of Departments $(\mathrm{N}=35)$.

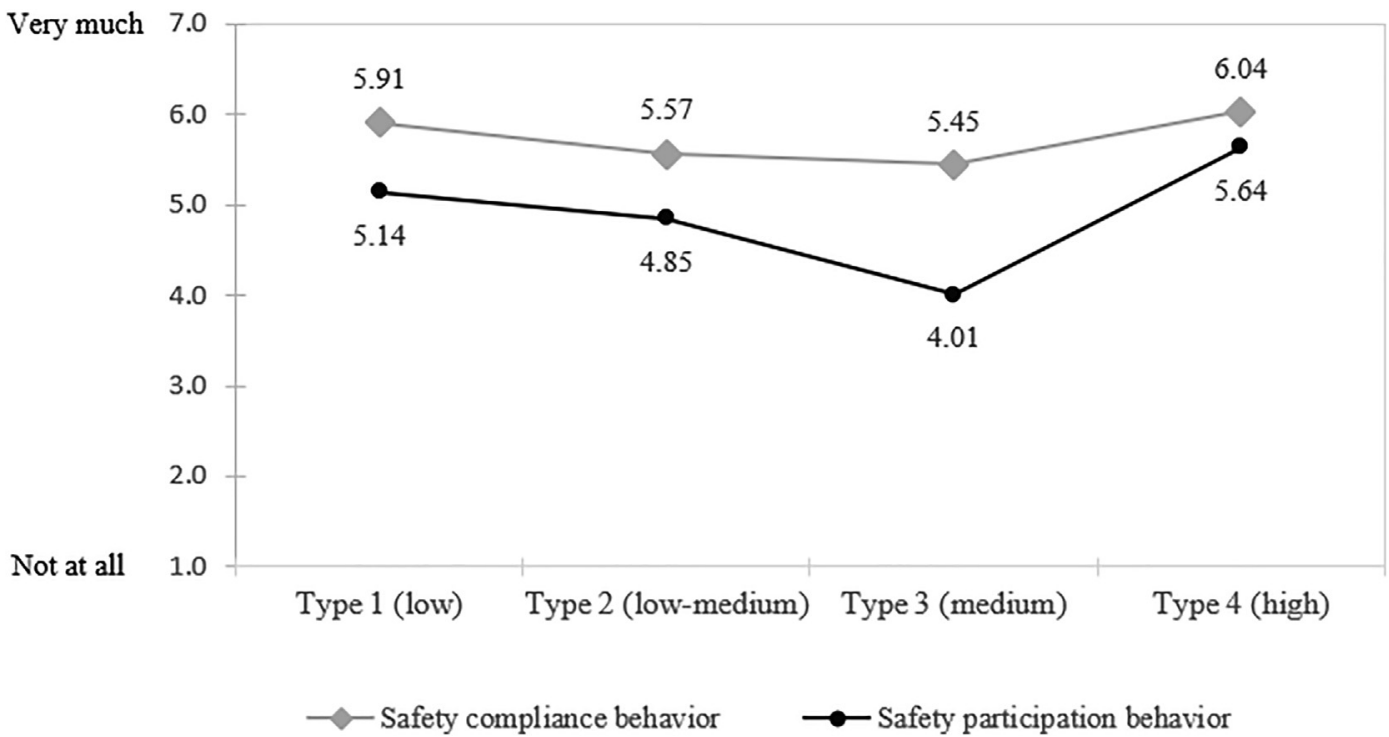

Fig. 2. Mean differences in safety compliance and safety participation behaviors according to the climate pattern.

- Safety participation behavior was significantly higher in types 1 and 2 in contrast with type 3 (Mean dif. type 1 vs type $3=1.13$, $p<0.001$; Mean dif. type 2 vs type $3=0.84, p<0.001$ ), and also for type 4 in contrast with all other types (Mean dif. type $4 \mathrm{vs}$ type $1=0.49, p=0.013$; type 4 vs type $2=0.79, p<0.001$; Mean dif. type $4 v s$ type $3=1.63, p<0.001$ ). 
Finally, a hierarchical multiple regression analysis was conducted at the individual-level to test the effects of climate patterns on safety behaviors, after controlling for the sociodemographic variables. As shown in Table 3, the climate patterns have a significant positive effect on safety behaviors. The results showed that, as the climate perceptions become more positive, the levels of safety participation and safety compliance increase as well (Beta $=0.365, \quad F \quad(3)=63.603, \quad p<0.001, \quad$ Beta $=0.248, \quad F \quad(3)$ $=30.381, p<0.001$, respectively), with a larger effect size for safety participation $\left(R^{2}\right.$ part $\left.=0.132\right)$ than for safety compliance $\left(R^{2}\right.$ part $=0.610$ ).

\section{Discussion}

The aim of this study was to identify how the associations between different specific climates define different patterns of climates and how they can affect safety behaviors, taking into account the multilevel nature of climate (organizational, supervisor, and coworkers' levels).

The clustering procedure allowed to group the departments into four types (clusters) with different hierarchical levels of climates; three of those types showed homogeneous patterns (with perceptions of low, medium and high climates), and one showed a heterogeneous pattern (with low and medium perceptions combined together).

A possible explanation for those results could lie in the fact that individuals develop a global perception of their organization and of their organizational procedures and practices (Schneider, 1975); specifically the patterns of climates investigated in the present study appeared to be more grounded in superior humanistic/ethical values (the fair treatment of all employees, their integration in some critical organizational processes such as communication and decision making and/or their involvement in informal and social networks), therefore it is plausible to expect that they will aggregate them showing some homogeneity of perceptions.

In addition to that, following Zwetsloot and colleagues' insights (2013), those core values such as participation (e.g., empowerment, social inclusion) trust, justice (e.g., diversity, equity, fairness), transparency and openness in communication are not fully independent; as stated by the authors, "justice and reliable information, even if it is bad news, generates credibility and confidence in safety management" (Zwetsloot et al., 2013, p. 189). Even in earlier studies it has been showed that there is a significant relationship among those constructs (Dekker, 2012; Giddens, 1991); therefore a positive safety culture is a just and trustable culture, where people are encouraged to deliver occupational health and safety relevant information (Reason, 1997).

Secondly, with regard to safety behaviors, the regression results showed that the higher the climates perceptions, the higher the levels of safety participation and safety compliance, with safety participation being more affected than compliance (higher effect size). The present results are in line with previous research (Paolillo et al., 2016), confirming the role of broader - non safety related climates on safety behaviors, particularly on safety participation; in the present study, those climates seemed to act as a bolster of the safety climate effect on both compliance and participation behaviors.

Moreover, there was a greater effect on safety participation than on safety compliance, with a larger effect size for safety participation compared to safety compliance; however, there were not enough departments to allow for intra-departments analyses. Nevertheless, those preliminary results look in line with previous studies showing that work environments that promote employee's engagement together with exposure to routine physical risks might represent an opportunity to intrinsically motivate to safety behavior (Carless, 2004; Griffin \& Curcuruto, 2016).

\subsection{Limitations, implications and further research}

The present study has some limitations, first of all the use of self-report data; reliance on self-report data have been criticized in the literature as it increases the likelihood of social desirability and common method bias (Howard, 1994). However, several authors have noted that self-report data are acceptable when it measures affective experiences or individual's self-perceptions, such as the variables of interest in this study (Maurer \& Tarulli, 1994; McEnrue, 1989; Spector, 1994). Additionally, the aggregation at the department level also reduced the likelihood of social desirability. Finally, it would be important that future research also consider the organizational level of analysis, by increasing the number of companies, due to the relatively limited number of organizations participating in the present study.

Despite these limitations, the theoretical strengths and practical implications of our work should be highlighted. Firstly, a major contribution of this study - derived from the use of cluster analysis - was to highlight the complex nature of organizational environments, as it responds to the need for more research about the possible additive and correlative effects of simultaneously existing

Table 3

Hierarchical regression results for safety compliance and safety participation behaviors.

\begin{tabular}{|c|c|c|c|}
\hline \multicolumn{2}{|c|}{ Independent variables } & \multicolumn{2}{|l|}{ Dependent variables } \\
\hline & & $\begin{array}{l}\text { Safety participation behavior } \\
\text { Beta }\end{array}$ & $\begin{array}{l}\text { Safety compliance behavior } \\
\text { Beta }\end{array}$ \\
\hline \multirow{5}{*}{ Control variables } & Male & 0.022 & 0.054 \\
\hline & Educational level & -0.037 & -0.027 \\
\hline & Seniority & 0.126 & 0.072 \\
\hline & & $\mathrm{R}_{\mathrm{a}}^{2}=0.010$ & $\mathrm{R}_{\mathrm{a}}^{2}=0.008$ \\
\hline & & $F(3,395)=2.301$ & $F(5,393)=0.597$ \\
\hline \multirow[t]{6}{*}{ Control variables } & Male & 0.026 & 0.033 \\
\hline & Educational level & -0.051 & -0.032 \\
\hline & Seniority & 0.141 & 0.084 \\
\hline & Climate patterns ${ }^{(1)}$ & $0.365^{* * *}$ & $0.248^{* * *}$ \\
\hline & & Total $R_{a}^{2}=0.147^{* * *}$ & Total $\mathrm{R}_{\mathrm{a}}^{2}=0.067^{* *}$ \\
\hline & & $F(6,392)=11.261$ & $F(8,390)=3.492$ \\
\hline
\end{tabular}

Note: standardized coefficients (Beta) were reported.

(1) The climate patterns are ordered ranging from low (1) to high (4).

$p<0.01$

*** $p<0.001$. 
climates (Schneider, Ehrhart, \& Macey, 2013) on specific secondlevel outcomes (Kuenzi \& Schminke, 2009).

In line with previous literature (DeJoy et al., 2004), the present findings show that several other organizational climate factors, such as fair treatment, integration, and involvement in the organizational mainstream and communication within the organization which had never been previously studied in their combined relationships - may also be associated with safety climate at different levels. Moreover the present findings also show that employees' safety performance extends beyond their perceptions of safety climate (Dejoy et al., 2004), as it also involves their perceptions of some relational aspects in the workplace (namely diversity, inclusiveness and communication)

Secondly, the present research focused on the department-level (instead of the individual level); in line with recent literature (Fugas et al., 2011), it stressed the importance for future safety intervention to be focused on the behavior of the whole team. Indeed, research has shown that the more ambiguous the target of perceptions and beliefs about environment is, the more individuals base their reality on group information (Fugas et al., 2011). The importance of those assumptions is also demonstrated through our findings, since they showed how the same company can have different, multiple clusters of climates associated to different work-departments. Therefore, our results suggest that this multiplicity of climate patterns should be considered in organizational interventions.

Another practical implication consistent with our results is the need for safety-training programs aimed at improving attitudes through the influence of peers (e.g., mentoring from coworkers; Raabe \& Beehr, 2003) besides the one of leaders (top management and supervisors), as yet hardly mentioned in the literature.

The present research represents the first study in this field and although caution should be used in the interpretation of our findings, some important implication for practice may be suggested. In particular, it is recommended that safety practitioners engage in more systematic organizational diagnosis, focusing on broader organizational factors that might affect safety (Hofmann \& Stetzer, 1996); management cannot presuppose that different departments from the same company share the same experiences of climates.

Therefore, in order to improve those climates, managers have to understand which factors cause differences in perceptions; such factors are, for example, the position of an employee in the communication network and the quality of his/her relationship with the direct supervisor and the other colleagues in the same department (Smidts et al., 2001).

\section{Conclusions}

The use of cluster analysis highlighted the complex nature of organizational environments, as it responded to the need for more research about the possible additive and correlative effects of simultaneously existing climates on safety behaviors.

In conclusion, the present study represents an innovative contribution to the literature on organizational climate and, in particular, to the field of safety. It suggests some new avenues for groundbreaking research focused on how empowerment, integration, and communication within work-units should be promoted and enforced.

\section{Data statement}

The datasets analyzed during the current study are available from the corresponding author on request.

\section{Funding}

This research did not receive any specific grant from funding agencies in the public, commercial, or not-for-profit sectors.

\section{Declaration of Competing Interest}

The authors declare that they have no known competing financial interests or personal relationships that could have appeared to influence the work reported in this paper.

\section{Acknowledgments}

The authors would like to thank the reviewers for the valuable and constructive feedback.

\section{References}

Andersen, L. P., Nørdam, L., Joensson, T., Kines, P., \& Nielsen, K. J. (2018). Socia identity, safety climate and self-reported accidents among construction workers. Construction Management and Economics, 36(1), 22-31.

Andriessen, J. H. T. H. (1978). Safe behaviour and safety motivation. Journal of Occupational Accidents, 1(4), 363-376.

Arbuckle, J. L. (2016), IBM ${ }^{\circledR}$ SPSS $^{\circledR}$ Amos $^{\mathrm{TM}}$ 24: Users Guide. USA: IBM.

Bandura, A. (1986). Social foundations for thought and action: A social cognitive theory. Englewood Cliffs, NJ: Prentice Hall.

Bauerle, T. J., Mcgonagle, A. K., \& Magley, V. J. (2016). Mere overrepresentation? Using cross-occupational injury and job analysis data to explain men's risk for workplace fatalities. Safety Science, 83, 102-113.

Beus, J. M., Dhanani, L. Y., \& McCord, M. A. (2015). A meta-analysis of personality and workplace safety: Addressing unanswered questions. Journal of Applied Psychology, 100(2), 481-498.

Beus, J. M., McCord, M. A., \& Zohar, D. (2016). Workplace safety: A review and research synthesis. Organizational psychology review, 6(4), 352-381.

Beyea, S. C. (2004). Creating a just safety culture. Aorn Journal, 79(2), 412-414.

Blau, P. M. (1964). Exchange and power in social life. New York: Wiley.

Breslin, F. C., \& Smith, P. (2005). Age-related differences in work injuries: A multivariate, population-based study. American Journal of Industrial Medicine, 48 (1), 50-56.

Brimhall, K. C., Lizano, E. L., \& Mor Barak, M. E. (2014). The mediating role of inclusion: A longitudinal study of the effects of leader-member exchange and diversity climate on job satisfaction and intention to leave among child welfare workers. Children and Youth Services Review, 40, 79-88.

Brondino, M. (2011). Agenti di clima e performance di sicurezza: un'analisi multilivello. Doctoral Dissertation, University of Verona, Italy.

Brondino, M., Pasini, M., \& Silva, S. (2013). Development and validation of an Integrated Organizational Safety Climate Questionnaire with multilevel confirmatory factor analysis. Quality and Quantity, 47, 2191-2223.

Brondino, M., Silva, S., \& Pasini, M. (2012). Multilevel approach to organizational and group safety performance: Coworkers as the missing link. Safety Science, 50 (9), 1847-1856.

Bronkhorst, B. (2015). Behaving safely under pressure: The effects of job demands, resources, and safety climate on employee physical and psychosocial safety behavior. Journal of Safety Research, 55, 63-72.

Burke, M. J., \& Signal, S. M. (2010). Workplace safety: A multilevel, interdisciplinary perspective. In Research in personnel and human resources management (pp. 1-47). Emerald Group Publishing Limited.

Campbell, J. (1990). The Army selection and classification project (Project A). Personnel Psychology, 43, 231-239.

Carless, S. A. (2004). Does psychological empowerment mediate the relationship between psychological climate and job satisfaction? Journal of Business and Psychology, 18, 405-406.

Casey, T. W., Griffin, M. A., Flatau Harrison, H., \& Neal, A. (2017). Safety climate and culture: Integrating psychological and systems perspectives. Journal of Occupational Health Psychology, 22(3), 341-353.

Cheyne, A., Cox, S., Oliver, A., \& Tomas, J. M. (1998). Modelling safety climate in the prediction of levels of safety activity. Work and Stress, 12(3), 255-271.

Chiaburu, D. S., \& Harrison, D. A. (2008). Do peers make the place? Conceptual synthesis and meta-analysis of coworker effects on perceptions, attitudes, OCBs, and performance. Journal of Applied Psychology, 93, 1082-1103.

Christian, M. S., Bradley, J. C., Wallace, J. C., \& Burke, M. J. (2009). Workplace safety: A meta-analysis of the roles of person and situation factors. Journal of Applied Psychology, 94, 1103-1127.

Clark, L. A., \& Watson, D. (1995). Constructing validity: Basic issues in objective scale development. Psychological assessment, 7(3), 309-319. doi: 10.1037| 1040-3590.7.3.309.

Clarke, S. (2006). The relationship between safety climate and safety performance: A metaanalytic review. Journal of Occupational Health Psychology, 11, 315327. 
Clarke, S. (2010). An integrative model of safety climate: Linking psychologica climate and work attitudes to individual safety outcomes using meta-analysis. Journal of Occupational and Organizational Psychology, 83(3), 553-578.

Clarke, S. (2012). The effect of challenge and hindrance stressors on safety behavior and safety outcomes: A meta-analysis. Journal of Occupational Health Psychology, 17(4), 387-397.

Cooper, M. D., \& Phillips, R. A. (2004). Exploratory analysis of safety climate and safety behaviour relationship. Journal of Safety Research, 35, 497-512.

Cornelissen, P. A., Van Hoof, J. J., \& De Jong, M. D. (2017). Determinants of safety outcomes and performance: A systematic literature review of research in four high-risk industries. Journal of Safety Research, 62, 127-141.

Cree, T., \& Kelloway, E. K. (1997). Responses to occupational hazards: Exit and participation. Journal of Occupational Health Psychology, 2(4), 304.

DeJoy, D., Schaffer, B., Wilson, M., Vandenberg, R., \& Butts, M. (2004). Creating safer workplaces: Assessing the determinants and role of safety climate. Journal of Safety Research, 35, 81-90.

Dekker, S. (2012). Just culture, balancing safety and accountability (2nd ed.) Aldershot, UK: Ashgate Publishers.

Dunlap, W. P., Burke, M. J., \& Smith-Crowe, K. (2003). Accurate tests of statistical significance for $\mathrm{r}_{\mathrm{wg}}$ and average deviation interrater agreement indexes. Journal of Applied Psychology, 88, 356-362.

Eisenberger, R., Fasolo, P., \& Davis-LaMastro, V. (1990). Perceived organizationa support and employee diligence, commitment, and innovation. Journal of Applied Psychology, 75, 51-59.

EUROSTAT (2018). Accidents at work statistics. Retrived on October 2018 from: https://ec.europa.eu/eurostat/statistics-explained/index.php/ Accidents_at_work_statistics

European Commission. (2018, November 11). Labour market information. Retrieved from https://ec.europa.eu/eures/main.jsp?countryld=IT\&acro=lmi\&show Region=true\&lang=en\&mode=text\&regionId=IT0\&nuts2Code=\%20\&nuts3Code= null\&catId $=412$

Fugas, C., Meliá, J. L., \& Silva, S. A. (2011). The "is" and the "ought": How perceived social norms influence safety behaviors at work? Journal of Occupational Health Psychology, 16(1), 67-79.

Fugas, C., Silva, S. A., \& Meliá, J. L. (2012). Another look at safety climate and safety behavior: Deepening the cognitive and social mediator mechanisms. Accident Analysis E' Prevention, 45, 468-477.

Gatien, B. (2010). An investigation into the relationship between perception of safety climate and organizational justice. Unpublished Doctoral Dissertation, Saint Mary's University, Halifax, Nova Scotia.

Giddens, A. (1991). The constitution of society (5th ed.). Cambridge, UK: Polity Press.

Gifi, A. (1990). Nonlinear multivariate analysis. Chichester: John Wiley and Sons.

Glendon, I. (2008). Safety culture: Snapshot of a developing concept. Journal of Occupational Health Safety, 24(3), 179-189.

Glisson, C., \& James, L. R. (2002). The cross-level effects of culture and climate in human service teams. Journal of Organizational Behavior, 23, 767-794.

Griffin, M. A., \& Curcuruto, M. (2016). Safety climate in organizations: new challenges and frontiers for theory, research and practice. Annual Review of Organizational Psychology and Organizational Behavior, 3, 191-212.

Griffin, M. A., \& Neal, A. (2000). Perceptions of safety at work: A framework for linking safety climate to safety performance, knowledge, and motivation. Journal of Occupational Health Psychology, 5, 347-358.

Guldenmund, F. W. (2000). The nature of safety culture: A review of theory and research. Safety Science, 34(1-3), 215-257.

Guzley, R. M. (1992). Organizational climate and communication climate: Predictors of commitment to the organization. Management Communication Quarterly, 5, 379-402.

Hahn, S. E., \& Murphy, L. R. (2008). A short scale for measuring safety climate. Safety Science, 46(7), 1047-1066.

Huang, Y. H., Zohar, D., Robertson, M. M., Garabet, A., Murphy, L. A., \& Lee, J. (2013) Development and validation of safety climate scales for mobile remote workers using utility/electrical workers as exemplar. Accident Analysis and Prevention, 59, 76-86.

Hair, J., Anderson, R., Tatham, R., \& e Black, W. (2010). Multivariate data analysis: A global perspective (7th ed.). Upper Saddle River: Pearson International Edition.

Hofmann, D. A., Burke, M. J., \& Zohar, D. (2017). 100 years of occupational safety research: From basic protections and work analysis to a multilevel view of workplace safety and risk. Journal of applied psychology, 102(3), 375-388.

Hofmann, D. A., Jacobs, R., \& Landy, F. J. (1995). High reliability process industries: Individual, micro, and macro organizational influences on safety performance. Journal of Safety Research, 26, 131-149.

Hofmann, D. A., \& Morgeson, F. P. (1999). Safety-related behavior as a social exchange: The role of perceived organizational support and leader- member exchange. Journal of Applied Psychology, 84, 286-296.

Hofmann, D. A., Morgeson, F. P., \& Gerras, S. J. (2003). Climate as a moderator of the relationship between leader-member exchange and content specific citizenship: Safety climate as an exemplar. Journal of Applied Psychology, 88, $170-178$.

Hofmann, D. A., \& Stetzer, A. (1996). A cross-level investigation of factors influencing unsafe behaviors and accidents. Personnel Psychology, 49, 307-339.

House, J. S. (1981). Work stress and social support. Reading, MA: Addison-Wesley.

Howard, G. S. (1994). Why do people say nasty things about self-reports? Journal of Organizational Behavior, 15, 399-404.

Ibarra, H. (1993). Personal networks of women and minorities in management: A conceptual framework. Academy of Management Review, 18, 56-87.
James, L. R. (1982). Aggregation bias in estimates of perceptual agreement. Journal of Applied Psychology, 67, 219-229.

James, L. R., Demaree, R. G., \& Wolf, G. (1993). Rwg: An assessment of within-group interrater agreement. Journal of Applied Psychology, 78, 306-309.

Jiang, L., Lavaysse, L. M., \& Probst, T. M. (2019). Safety climate and safety outcomes: A meta-analytic comparison of universal vs. industry-specific safety climate predictive validity. Work E Stress, 33(1), 41-57.

Jiang, L., Yu, G., Li, Y., \& Li, F. (2010). Perceived colleagues' safety knowledge/ behavior and safety performance: Safety climate as a moderator in a multilevel study. Accident Analysis and Prevention, 42(5), 1468-1476.

Johnson, H. (1988). Job strain, work place social support, and cardiovascular disease: A cross-sectional study of a random sample of the Swedish working population. American Journal of Public Health, 78(10), 1336-1342.

Kaplan, D., Wiley, J., \& Maertz, C. (2011). The role of calculative attachment in the relationship between diversity climate and retention. Human Resource Management, 50(2), 271-287.

Karasek, R., \& Theorell, T. (1990). Healthy work: Stress, productivity, and the reconstruction of working life. New York: Basic Books.

Karttunen, J. P., \& Rautiainen, R. H. (2016). 362 Gender differences in work tasks and injuries in agriculture. Injury Prevention, 22, A132-A133.

Kachan, D., Fleming, L. E., LeBlanc, W. G., Goodman, E., Arheart, K. L., CabanMartinez, A. J., et al. (2012). Worker populations at risk for work-related injuries across the life course. American Journal of Industrial Medicine, 55(4), 361-366.

Kim, S. J., \& Chung, E. K. (2019). The effect of organizational justice as perceived by occupational drivers on traffic accidents: Mediating effects of job satisfaction. Journal of Safety Research, 68, 27-32.

Kim, S. S., Dutra, L. M., \& Okechukwu, C. A. (2014). Contractor-, steward-, and coworker-safety practice: Associations with musculoskeletal pain and injuryrelated absence among construction apprentices. International Archives of Occupational and Environmental Health, 87(5), 493-500.

Konkolewsky, H. H. (2004). Actions to Improve Safety and Health in Construction (No. 1608-4144). Luxembourg: European Agency for Safety and Health at Work

Kozlowski, S. W., \& Klein, K. J. (2000). A multilevel approach to theory and research in organizations: Contextual, temporal, and emergent processes. In K. J. Kline \& S. W. Kozlowski (Eds.), Multilevel theory, research, and methods in organizations (pp. 3-90). San Francisco: Jossey-Bass.

Kuenzi, M., \& Schminke, M. (2009). Assembling fragments into a lens: A review, critique, and proposed research. Agenda for the organizational work climate literature. Journal of Management, 35(3), 634-717.

Lindell, M. K., \& Brandt, C. J. (2000). Climate quality and climate consensus as mediators of the relationship between organizational antecedents and outcomes. Journal of Applied Psychology, 85, 331-348.

Liu, X., Huang, G., Huang, H., Wang, S., Xiao, Y., \& Chen, W. (2015). Safety climate, safety behavior, and worker injuries in the Chinese manufacturing industry. Safety Science, 78, 173-178.

Marks, M. A., Mathieu, J. E., \& Zaccaro, S. J. (2001). A temporally based framework and taxonomy of team processes. Academy of Management Review, 26(3), 356-376.

Maurer, T., \& Tarulli, B. (1994). Perceived environment, perceived outcome, and person variables in relationship to voluntary development activity by employees. Journal of Applied Psychology, 79, 3-14.

McEnrue, M. P. (1989). The perceived fairness of managerial promotion practices. Human Relations, 42, 815-827.

McKay, P. F., Avery, D. R., \& Morris, M. A. (2008). Mean racial-ethnic differences in employee sales performance: The moderating role of diversity climate. Personnel Psychology, 61, 349-374.

McKay, P. F., Avery, D. R., \& Morris, M. A. (2009). A tale of two climates: Diversity climate from subordinates' and managers' perspectives and their role in store unit sales performance. Personnel Psychology, 62, 767-791.

McNeely, R. L. (1992). Job satisfaction in the public social services: Perspectives on structure, situational factors, gender, and ethnicity. In Y. Hasenfeld (Ed.), Human services as complex organizations (pp. 224-256). Newbury Park, CA: Sage.

Meliá, J. L., Mearns, K., Silva, S., \& Lima, M. L. (2008). Safety climate responses and the perceived risk of accidents in the construction industry. Safety Science, 46, 949-958.

Meliá, J. L., \& Sesé, A. (2007). Supervisors safety response: A multisample confirmatory factor analysis. Psicothema, 19(2), 231-238.

Milliken, F. J., \& Martins, L. L. (1996). Searching for common threads: Understanding the multiple effects of diversity in organizational groups. Academy of Management Review, 21(2), 402-433.

Mor Barak, M. E., \& Cherin, D. A. (1998). A tool to expand Organizational understanding of workforce diversity: Developing a measure of InclusionExclusion. Administration in Social Work, 22(1), 47-64.

Mor Barak, M. E., Cherin, D. A., \& Berkman, S. (1998). Organizational and personal dimensions in diversity climate: Ethnic and gender differences in employee perceptions. Journal of Applied Behavioral Science, 34, 82-104.

Mor Barak, M. E., \& Levin, A. (2002). Outside of the corporate mainstream and excluded from the work community: A study of diversity, job satisfaction and well-being. Community, Work E' Family, 5, 133-157.

Nahrgang, J. D., Morgeson, F. P., \& Hofmann, D. A. (2011). Safety at work: A metaanalytic investigation of the link between job demands, job resources, burnout, engagement, and safety outcomes. Journal of Applied Psychology, 96, 71-94.

National Institute for Insurance against Workplace Accidents and Occupational Disease. (2018). Dati INAIL 2018. Retrieved from https://www.inail.it/cs/ internet/docs/alg-dati-inail-2018-giugno.pdf 
Neal, A. \& Griffin, M. A. (1997). Perceptions of Safety at Work: Developing a Model to Link Organizational Safety Climate and Individual Behavior. Paper presented to the 12th Annual Conference of the Society for Industrial and Organizational Psychology, St. Louis, MO.

Neal, A., Griffin, M. A., \& Hart, P. M. (2000). The impact of organizational climate on safety climate and individual behavior. Safety Science, 34, 99-109.

Nishii, L. H. (2013). The benefits of climate for inclusion for gender-diverse groups. Academy of Management Journal, 56(6), 1754-1774.

Nissly, J. A., Mor Barak, M. E., \& Levin, A. (2005). Stress, social support, and workers' intentions to leave their jobs in public child welfare. Administration in Social Work, 29(1), 79-100.

O'Leary, V. E., \& Ickovics, J. R. (1992). Cracking the glass ceiling: Overcoming isolation and discrimination. In U. Sekeran \& F. Leong (Eds.), Womanpower: Managing in times of demographic turbulence (pp. 7-30). Beverly Hills, CA: Sage.

Oliver, A., Cheyne, A., Tomas, J. M., \& Cox, S. (2002). The effects of organizational and individual factors on occupational accidents. Journal of Occupational and Organizational Psychology, 75, 473-488.

Paolillo, A., Pasini, M., Silva, S. A., \& Magnano, P. (2016). Psychometric properties of the Italian adaptation of the Mor Barak et al. diversity climate scale. Quality $\mathcal{E}^{\prime}$ Quantity, 51(2), 873-890. https://doi.org/10.1007/s11135-016-0316-3.

Paolillo, A., Silva, S. A., \& Pasini, M. (2016). Promoting safety participation through diversity and inclusion climates. International Journal of Workplace Health Management, 9(3), 308-327. https://doi.org/10.1108/IJWHM-01-20150002.

Raabe, B., \& Beehr, T. A. (2003). Formal mentoring versus supervisor and coworker relationships: Differences in perceptions and impact. Journal Organizational Behavior, 24, 271-293.

Reason, J. T. (1997). Managing the risks of organisational accidents. Aldershot, UK: Ashgate.

Reichers, A. E. (1985). A review and reconceptualization of organizational commitment. Academy of Management Review, 10, 465-476.

Schneider, B. (1975). Organizational climates: An essay. Personnel Psychology, 28, $447-479$.

Schneider, B., Ehrhart, M. G., \& Macey, W. (2013). Organizational Climate and Culture. Annual Review of Psychology, 64, 361-388.

Schneider, B., \& Reichers, A. E. (1983). On the etiology of climates. Personnel Psychology, 36, 19-39.

Schonfeld, I. S., \& Chang, C.-H. (2017). Occupational Health Psychology: Work, stress, and health. New York: Springer Publishing Company.

Seabury, S. A., Terp, S., \& Boden, L. I. (2017). Racial and ethnic differences in the frequency of workplace injuries and prevalence of work-related disability. Health Affairs (Project Hope), 36(2), 266-273. Web.

Shannon, H. S., Mayr, J., \& Haines, T. (1997). Overview of the relationship between organizational and workplace factors and injury rates. Safety Science, 26, 201-217.

Shore, L. M., Randel, A. E., Chung, B. G., Dean, M. A., Ehrhart, K. H., \& Singh, G. (2011). Inclusion and diversity in work groups: A review and model for future research. Journal of Management, 37, 1262-1289.

Shrout, P. E., \& Fleiss, J. L. (1979). Intraclass correlations: Uses in assessing rater reliability. Psychological Bulletin, 86, 420-428.

Silva, S. A., \& Fugas, C. S. (2015). The influence of peer norms. In S. Clarke, T. M. Probst, F. Guldenmund, \& J. Passmore (Eds.), The Wiley Blackwell handbook of the psychology of occupational safety and workplace health (pp. 61-82). NJ: WileyBlackwell.

Silva, S., Lima, M. L., \& Baptista, C. (2004). OSCI: An organisational and safety climate inventory. Safety Science, 42, 205-220.

Silva, S., Araújo, A., Costa, D., \& Meliá, J. L. (2013). Safety climates in construction industry: Understanding the role of construction sites and workgroups. Open Journal of Safety Science and Technology, 4, 80-86.

Singer, S., Meterko, M., Baker, L., Gaba, D., Falwell, A., \& Rosen, A. (2007). Workforce perceptions of hospital safety culture: Development and validation of the patient safety climate in healthcare organizations survey. Health Services Research, 42(5), 1999-2021.

Smidts, A., Pruyn, A. T. H., \& Riel, C. B. M. (2001). The impact of employee communication and perceived external prestige on organisational identification. Academy of Management Journal, 49(5), 1051-1062.

Smith, C. K., \& Anderson, N. J. (2017). Work-related Injuries among commercial janitors in Washington State, comparisons by gender. Journal of Safety Research, 62, 199-207.

Smith, P. M., \& Berecki-Gisolf, J. (2014). Age, occupational demands and the risk of serious work injury. Occupational Medicine, 64(8), 571-576.

Smith-Jentsch, K. A., Mathieu, J. E., \& Kraiger, K. (2005). Investigating linear and interactive effects of shared mental models on safety and efficiency in a field setting. Journal of Applied Psychology, 90(3), 523.

Spector, P. E. (1994). Using self-report questionnaires in OB research: A comment on the use of a controversial method. Journal of Organizational Behavior, 15, 385-392.

Stegmann, S. (2011). Engaging with diversity of social units - A social identity perspective on diversity in organizations. Unpublished doctoral dissertation, Goethe University, Frankfurt am Main, Germany.

Tak, S., Alterman, T., Baron, S., \& Calvert, G. M. (2010). Racial and ethnic disparities in work-related injuries and socio-economic resources among nursing assistants employed in US nursing homes. American Journal of Industrial Medicine, 53(10), 951-959.

Törner, M., Pousette, A., Larsman, P., \& Hemlin, S. (2016). Coping with paradoxical demands through an organizational climate of perceived organizational support: An empirical study among workers in construction and mining industry. Journal of Applied Behavioral Science, 53(1), 117-141.

Tucker, S., Chmiel, N., Turner, N., Hershcovis, M. S., \& Stride, C. B. (2008). Perceived organizational support for safety and employee safety voice: The mediating role of coworker support for safety. Journal of Occupational Health Psychology, 13(4), 319-330.

Tucker, S., Diekrager, D., Turner, N., \& Kelloway, E. K. (2014). Work-related injury underreporting among young workers: Prevalence, gender differences, and explanations for underreporting. Journal of Safety Research, 50, 67-73.

Turner, B. A. (1978). Man-made disasters. Oxford, UK: Wykeham.

Van Der Kooij, A. J., Meulman, J., \& Heiser, W. (2006). Local minima in categorical multiple regression. Computational Statistics and Data Analysis, 50(2), 446-462.

Viswesvaran, C., Sanchez, J. I., \& Fisher, J. (1999). The role of social support in the process of work stress: A meta-analysis. Journal of Vocational Behavior, 54(2), 314-334.

Wallace, J. C., Popp, E., \& Mondore, S. (2006). Safety climate as a mediator between foundation climates and occupational accidents: A group-level investigation. Journal of Applied Psychology, 91, 681-688.

Weiner, B. J., Hobgood, C., \& Lewis, M. A. (2008). The meaning of justice in safety incident reporting. Social Science E' Medicine, 66, 403-413.

Westaby, J. D., \& Lowe, J. K. (2005). Risk-taking orientation and injury among youth workers: Examining the social influence of supervisors, coworkers, and parents. Journal of Applied Psychology, 90(5), 1027-1035.

Whitman, D. S., Caleo, S., Carpenter, N., Horner, M. T., \& Bernerth, J. B. (2012). Fairness at the collective level: A meta-analytic examination of the consequences and boundary conditions of organizational justice climate. Journal of Applied Psychology, 97(4), 776-791.

Zhang, R. P., Pirzadeh, P., Lingard, H., \& Nevin, S. (2018). Safety climate as a relative concept: Exploring variability and change in a dynamic construction project environment. Engineering, Construction and Architectural Management, 25(3), $298-316$.

Zohar, D. (1980). Safety climate in industrial organizations: Theoretical and applied implications. Journal of Applied Psychology, 65(1), 96-102.

Zohar, D. (2000). A group-level model of safety climate: Testing the effect of group climate on microaccidents in manufacturing jobs. Journal of Applied Psychology, $85,587-596$

Zohar, D. (2003). Safety climate: Conceptual and measurement issues. In J. C. Quick \& L. E. Tetrick (Eds.), Handbook of occupational health psychology (pp. 123-142). Washington, DC: American Psychology Association.

Zohar, D. (2008). Safety climate and beyond: A multi-level multi-climate framework. Safety Science, 46, 376-387.

Zohar, D. (2010). Thirty years of safety climate research: Reflections and future directions. Accident Analysis and Prevention, 42, 1517-1522.

Zohar, D., \& Luria, G. (2005). A multilevel model of safety climate: Cross-level relationships between organization and group-level climates. Journal of Applied Psychology, 90, 616-628.

Zohar, D., \& Tenne-Gazit, O. (2008). Transformational leadership and group interaction as climate antecedents: A social network analysis. Journal of Applied Psychology, 93, 744-757.

Zohar, D. (2014). Safety climate: Conceptualization, measurement, and improvement. The Oxford Handbook of Organizational Climate and Culture, 317-334.

Zohar, D., Huang, Y. H., Lee, J., \& Robertson, M. (2015). Testing extrinsic and intrinsic motivation as explanatory variables for the safety climate-safety performance relationship among long-haul truck drivers. Transportation Research Part F Psychology and Behaviour, 30, 84-96.

Zwetsloot, G. I. J. M., van Scheppingen, A. R., Bos, E. H., Dijkman, A., \& Starren, A (2013). The core values that support health, safety, and well-being at work. Safety and Health at Work, 4(4), 187-196.

Anna Paolillo is Lecturer in the Department of Management at Kingston Business School, Kingston University London. She has been teaching courses related with Work Psychology and Organizational Behavior in several Undergraduate Degrees and Master, mainly in Occupational Psychology and Business Management Degrees; she has also experience as a researcher and consultant at international levels in the education, manufacturing and infrastructure sectors. Her main research topics are related to health and wellbeing at work, specifically: diversity management and inclusion as related to safety climate, safety performance and organizational citizenship behavior, communication climate and psychological capital.

Sílvia Silva is Associate Professor in the Department of Human Resources and Organizational Behavior, at ISCTE - Instituto Universitário Lisboa. She is a senior researcher at BRU-IUL. She has been teaching courses related with Work Psychology, Organizational Behavior and Research Methods in several Undergraduate Degrees, Master and PhD, mainly in Psychology and Management Degrees. Her main research is in the field of organizational psychology applied to occupational safety and wellbeing. She has been studying, for instance, prevention behaviors and participative/initiative behaviors at work, groups norms and climate (focusing peers and supervisors), organizational and safety climate and learning with accidents/ incidents.

Helena Carvalho is a sociologist and full professor at ISCTE - University Institute of Lisbon. She is the Director of School of Sociology and Public Policy at ISCTE University Institute of Lisbon. She coordinates a postgraduate in Data Analysis in Social Sciences. She is an expert in methodological issues and data analysis and a senior researcher at the Center for the Research and Study of Sociology (CIES- IUL). 
Her research is focused on the quantitative and multivariate methods for categorical variables, mainly methods of interdependence, dependence and multileve models. She has been participating in several research projects, developing her skills in data analysis with quantitative methods. She has published several books and articles in Portugal and abroad.

Margherita Pasini is Associate Professor in Psychometrics at University of Verona Department of Philosophy, Education and Psychology, Faculty of Educational Sciences from 2004. She has been teaching courses related with Methodology of psychological research, Psychometrics and Statistics for psychological research in several Undergraduate Degrees, Master and $\mathrm{PhD}$, mainly in Science of Training in the Organizations Degrees and Organizational Psychology Doctorate. Her main research topics are: psychometrics and data analysis in psychology (validation of measurement instruments, multivariate analyses, multi-level modeling); Organizational Psychology (Organizational well-being; motivation and commitment; safety climate and safety behaviours; coping strategies; job insecurity; learning processes in organizations).

Appendix 1. Table with correspondences between the work departments and numbers in Fig. 2.

\begin{tabular}{|c|c|c|c|}
\hline & Departments & Number of workers & Corresponding Number in the Cluster Analysis \\
\hline \multirow[t]{11}{*}{ Company 1} & Big Machine Welding & 5 & 22 \\
\hline & Big Machine Rolling & 7 & 23 \\
\hline & Big Machine Impregnation & 7 & 24 \\
\hline & Big Machine Painting & 4 & 26 \\
\hline & Medium Generator Rolling & 19 & 27 \\
\hline & Medium Generator Assembling & 27 & 28 \\
\hline & Mechanic Manufacturing & 37 & 31 \\
\hline & Mechanic Shear-off & 23 & 32 \\
\hline & Mechanic Maintenance & 6 & 33 \\
\hline & Packaging \& Shipping & 11 & 34 \\
\hline & Logistic Storage & 7 & 35 \\
\hline \multirow{7}{*}{ Company 2} & Repairing & 20 & 2 \\
\hline & Welding & 9 & 3 \\
\hline & Manufacturing Boilers & 11 & 4 \\
\hline & Painting & 5 & 5 \\
\hline & Quality Control & 4 & 6 \\
\hline & Maintenance & 5 & 7 \\
\hline & Shipping & 4 & 9 \\
\hline \multirow[t]{5}{*}{ Company 3} & Painting & 13 & 12 \\
\hline & Packaging and Shipping & 3 & 13 \\
\hline & Manufacturing & 8 & 14 \\
\hline & Assembling & 11 & 15 \\
\hline & Preparation \& Loading & 13 & 16 \\
\hline
\end{tabular}


Appendix 2. Table of frequencies - types of climate patterns per department (the number under each type corresponds to the number of workers within that department)

\begin{tabular}{|c|c|c|c|c|c|c|c|}
\hline \multicolumn{3}{|c|}{ Company } & \multicolumn{4}{|c|}{ Typology } & \multirow[t]{2}{*}{ Total } \\
\hline & & & Type 1 & Type 2 & Type 3 & Type 4 & \\
\hline \multirow[t]{9}{*}{1} & Department & 1 & 0 & 0 & 34 & 0 & 34 \\
\hline & $(\mathrm{N}=8)$ & 10 & 0 & 0 & 0 & 20 & 20 \\
\hline & & 21 & 0 & 0 & 0 & 9 & 9 \\
\hline & & 31 & 0 & 0 & 11 & 0 & 11 \\
\hline & & 32 & 0 & 0 & 0 & 5 & 5 \\
\hline & & 33 & 0 & 0 & 0 & 4 & 4 \\
\hline & & 34 & 0 & 0 & 0 & 5 & 5 \\
\hline & & 35 & 0 & 4 & 0 & 0 & 4 \\
\hline & Total & & 0 & 4 & 45 & 43 & 92 \\
\hline \multirow[t]{7}{*}{2} & Department & 2 & 0 & 13 & 0 & 0 & 13 \\
\hline & $(N=6)$ & 3 & 0 & 3 & 0 & 0 & 3 \\
\hline & & 4 & 8 & 0 & 0 & 0 & 8 \\
\hline & & 5 & 11 & 0 & 0 & 0 & 11 \\
\hline & & 6 & 0 & 13 & 0 & 0 & 13 \\
\hline & & 7 & 6 & 0 & 0 & 0 & 6 \\
\hline & Total & & 25 & 29 & 0 & 0 & 54 \\
\hline \multirow[t]{5}{*}{3} & Department & 8 & 0 & 0 & 13 & 0 & 13 \\
\hline & $(\mathrm{N}=4)$ & 9 & 0 & 0 & 4 & 0 & 4 \\
\hline & & 11 & 0 & 12 & 0 & 0 & 12 \\
\hline & & 12 & 0 & 0 & 3 & 0 & 3 \\
\hline & Total & & 0 & 12 & 20 & 0 & 32 \\
\hline \multirow[t]{18}{*}{4} & Department & 13 & 0 & 0 & 5 & 0 & 5 \\
\hline & $(\mathrm{N}=17)$ & 14 & 0 & 0 & 7 & 0 & 7 \\
\hline & & 15 & 0 & 0 & 0 & 7 & 7 \\
\hline & & 16 & 0 & 24 & 0 & 0 & 24 \\
\hline & & 17 & 0 & 4 & 0 & 0 & 4 \\
\hline & & 18 & 0 & 0 & 19 & 0 & 19 \\
\hline & & 19 & 0 & 27 & 0 & 0 & 27 \\
\hline & & 20 & 0 & 0 & 20 & 0 & 20 \\
\hline & & 22 & 5 & 0 & 0 & 0 & 5 \\
\hline & & 23 & 0 & 37 & 0 & 0 & 37 \\
\hline & & 24 & 0 & 0 & 23 & 0 & 23 \\
\hline & & 25 & 0 & 0 & 6 & 0 & 6 \\
\hline & & 26 & 0 & 0 & 11 & 0 & 11 \\
\hline & & 27 & 0 & 0 & 7 & 0 & 7 \\
\hline & & 28 & 0 & 0 & 12 & 0 & 12 \\
\hline & & 29 & 0 & 6 & 0 & 0 & 6 \\
\hline & & 30 & 0 & 0 & 7 & 0 & 7 \\
\hline & Total & & 5 & 99 & 117 & 7 & 228 \\
\hline
\end{tabular}

